\title{
ПРОТИВОДЕЙСТВИЕ КОРРУПЦИИ В ЧАСТНОМ БИЗНЕСЕ СО СТОРОНЫ МЕЖДУНАРОДНОЙ ФИНАНСОВОЙ КОРПОРАЦИИ
}

\author{
(C) 2021 Кудряшов Владислав Васильевич \\ кандидат исторических наук, доцент \\ действительный государственный советник Российской Федерации 3 класса \\ доцент кафедры гражданского права Юридического факультета \\ Московский государственный областной университет, Россия, Москва \\ E-mail: kudryashov.minfin@ya.ru
}

Финансирование частного бизнеса происходит из разных источников, как-то: выпуск корпоративных ценных бумаг - акций и облигаций, государственная поддержка в различных формах, внутренние и внешние частные займы и др. В каждой из моделей финансирования у займодавца имеются свои требования к заемщику, кроме того, отдельные обстоятельства могут возникнуть уже в процессе финансирования. В предлагаемом материале речь пойдет о некоторых особенностях финансирования частного бизнеса со стороны международной финансовой организации - Международной финансовой корпорации, а именно - о ее требованиях в сфере борьбы с коррупцией в частном бизнесе.

Ключевые слова: Международная финансовая корпорация, коррупция, санкции, частное предпринимательство.

Международная финансовая корпорация (International Finance Corporation, IFC) [1] (Kopпорация) - международная финансовая организация, входящая в Группу Всемирного банка (ГВБ), учреждена международным договором (Статьи соглашения МФК) в 1956 г. в целях содействия частному предпринимательству в развивающихся странах.

Согласно ст. 1 Статей целями Корпорации являются содействие экономическому развитию путем поддержки роста частных компаний в государствах-членах Корпорации, в особенности в наименее развитых регионах. В ходе достижения указанной цели Корпорация уполномочена сотрудничать с частными инвесторами; финансировать создание и развитие частных предприятий; осуществлять инвестиции без гарантии их возмещения правительствами; обеспечивать объединение внутреннего и иностранного частного капитала с опытным менеджментом; способствовать привлечению частного местного и зарубежного капитала и др.

Подход МФК к деятельности в сфере содействия своим финансированием глобальному и региональному устойчивому развитию регулируется Платформой устойчивого развития (Sustainability Framework) [2] и Методологией корпоративного управления [3]. Эти докумен- ты призваны помочь клиентам МФК - частным компаниям повысить эффективность бизнеса, его прозрачность, наладить отношения с лицами, чьи интересы затронуты проектами, финансируемыми МФК, защитить окружающую среду и др.

Следуя глобальном тренду усиления противодействия коррупции в экономике и бизнесе, МФК проводит соответствующие мероприятия в русле общей политики ГВБ в этой сфере, разработанной головной организацией Группы Международным банком реконструкции и развития (МБРР, Банк).

Комплекс документов, регламентирующих применение санкций к лицам, замеченным в недобросовестном и нечистоплотном поведении в процессе финансирования проектов, именуется Система санкций Группы Всемирного банка (ГВБ), и включает различные регламенты, руководства и меры политики [4], а также рекомендации и положения, в частности, такие, как Рекомендации Всемирного банка по предупреждению и борьбе с мошенничеством и коррупцией в проектах, финансируемых за счет займов МБРР и кредитов и грантов МАР, положения которых включаются непосредственно или в виде ссылок в юридические соглашения Банка с заемщиками [5], Положение о закупках для заемщиков, финансирую- 
щих инвестиционные проекты [6] и др.

Согласно общему единому подходу ГВБ под санкциями понимается «любая мера, установленная Группой Всемирного банка, которая будет введена соответствующим сотрудником Системы санкций в отношении стороны, признанной виновной или ответственной за подсанкционную практику» [7]. Санкции предназначены как для предотвращения будущих проступков, так и для поощрения реабилитации сторон, на которые были наложены санкции.

Применение санкций представляет собой формализованный двухуровневый административный процесс, призванный защитить добросовестность (integrity) при проведении операций Всемирного банка и обеспечить использование финансирования развития только на намеченные объекты [8]. Реализацией соответствующих административных процедурам Банк определяет, следует ли применять санкции к сторонам, которые, подозреваются в подсанкционной практике в связи с финансируемым Банком проектом, виды и сроки наложения таких санкций и их отмены.

Санкционные системы других международных финансовых организаций, входящих в Группу, в частности МФК, в целом аналогичны системе МБРР и созданы на основе документов МБРP.

Так, согласно Определениям и интерпретацзии санкций МФК к подсанкционной практике относятся такие действия, как мошенничество (fraud), коррупция (corruption), сговор (collusion), принуждение (coercion) и воспрепятствование (расследованию) (obstruction) [9].

Под «коррупционной практикой» понимается «предложение, предоставление, получение или вымогательство, прямо или косвенно, чего-либо ценного, чтобы повлиять ненадлежащим образом на действия другой стороны» [10].

Процесс применения санкций является двухуровневым административным процессом, поскольку изначально причастность к подсанкционной практике исследуется Управлением по борьбе с мошенничеством Группы Всемирного банка (INT), после чего дело направляется Сотруднику по оценке МФК (IFC's Evaluation Officer) [11].

Сотрудник по оценке МФК, проанализировав полученную информацию и собрав при необходимости дополнительные данные, принимает решение о наложении санкций либо об отказе в их наложении. В случае наложения санкций если компания или физическое лицо отказываются от их оспаривания, то решение вступает в силу, а если оспаривают, то дело направляется в Cовет по санкциям Группы Всемирного банка [12].

Большинство членов Совета по санкциям являются старшими лицами (senior figures), не связанными с Группой Всемирного банка. Совет по санкциям принимает окончательное решение по делу. МФК не может отменить такое решение.

На период рассмотрения дела контрагенты МФК, которые замешаны в «подсанкционной» практике, могут быть «отстранены» от проекта. Процесс санкций применяется к любому контрагенту МФК, который включает компании и частные лица-заемщики; компании, в которые МФК инвестирует (прямые или портфельные инвестиции); компании, которые занимают или выпускают долговые ценные бумаги при поддержке гарантий МФК; спонсоры; получатели консультационных услуг; консультанты и советники, предоставляющие консультационные услуги.

Инструкция по применению санкций в МФК принята в 2012 г. [13] и содержит детальное описание процесса расследования случаев коррупционной и иной подсанкционной практики, порядка рассмотрения обращений сторон, действий уполномоченных сотрудников МФК, сроков действия санкций и условий их снятия, и т.д. [14]

Так, Инструкцией предусмотрено пять возможных административных санкций: публичное письмо с осуждением (public letter of reprimand), отстранение (debarment), условное неотстранение (conditional non-debarment), отстранение с восстановлением по выполнении условий (debarment with conditional release или восстановление (restitution).

Отстранение с условным восстановлением (debarment with conditional release) является стандартной или «базовой» санкцией по делам, инициированным в соответствии с пересмотренными процедурами санкций, принятыми ГВБ в 2011 г. Усилия по исполнению или совершенствованию мер по исполнению Программы соблюдения добросовестности, приемлемой для ГВБ, является основным условием прекращения отстранения (или условного неотстранения); или в случае уже наложенных ограничений досрочного прекращения срока их действия.

Личность каждой попавшей под санкции 
стороны и введенные санкции должны быть публично раскрыты.

Любые юридические соглашения между попавшей под санкции стороной и МФК будут по-прежнему регулироваться применимым правом, соответствующими соглашениями и положениями о разрешении споров, изложенными в соглашениях.

Однако в силу соглашения о перекрестном отстранении, заключенного в 2010 г. между Группой Африканского банка развития, Азиатским банком развития, Европейским банком реконструкции и развития, Межамериканским банком развития и Группой Всемирного банка (международные банки развития, МБР) [15] международными банками развития признаются и взаимно обеспечиваются действия друг друга по отстранению коррупционеров, а также взаимно признаются четырех унифицированных формы подсанкционной практики - коррупции, мошенничества, принуждения и сговора. Этим соглашением учреждена инновационная скоординированная глобальная инициатива и создан серьезный сдерживающий фактор для частного бизнеса от участия или совершения мошеннических или коррупционных действий в проектах развития, финансируемых МБР, и дает бизнесу стимул для очищения своей деятельности от подобных проявлений [16].

Таким образом, меры, принимаемые в МФК против проявлений коррупции и мошенничества при финансировании проектов развития в частном секторе, являются частью общего антикоррупционного механизма Группы Всемирного банка. При этом выявление «подсанкционных» действий может осуществляться как силами са- мой МФК, так и аппаратом МБРР.

Рассмотрение и проверка информации о фактах коррупции и наложение санкций осуществляет специальный служащий МФК, но в качестве апелляционной инстанции для оспаривания решений о наложении санкций в Группе Всемирного банка действует единый орган Совет по санкциям.

Санкции МФК в отношении лиц, замешанных в коррупционной практике, квалифицируются как специальный правовой режим одностороннего действия, созданный международной финансовой организацией и направленный на специальные субъекты - частные организациизаемщики, совершившие действия, запрещенные соответствующими внутренними регламентами МФК.

Этот механизм относится к внутреннему праву международной финансовой организации, и формально не должен выходить за рамки двухсторонних отношений МФК-клиент и влиять на отношения клиента с другими компаниями, лицами и международными организациями.

Тем не менее, отметим, что так называемый «режим взаимного признания решений о наложении санкций», созданный мировыми международными банками развития и МБРР на основании соответствующего соглашения [17], может существенно уменьшить возможности получения финансирования частным лицом, подвергнутым санкциям в одном из них за коррупционные проявления, что позволяет говорить о формировании глобального антикоррупционного правового режима в сфере финансирования развития частного сектора в развивающихся странах.

\section{Библиографический список}

1. Международная финансовая корпорация. URL: http://www.cofe.ru/finance/russian/12/32.htm (дата обращения: 11.12.2014).

2. IFC Sustainability Framework. URL: https://www.ifc.org/wps/wcm/connect/topics_ext_content/ifc_external_ corporate_site/sustainability-at-ifc/policies-standards/sustainability+framework (дата обращения: 27.10.2018).

3. IFC Corporate Governance Methodology. URL: https://www.ifc.org/wps/wcm/connect/topics_ext_content/ ifc_external_corporate_site/ifc+cg/investment+services/corporate+governance+methodology (дата обращения: 27.10.2018).

4. Bank Procedure: Sanctions Proceedings and Settlements in Bank Financed Projects, 2016. URL: https://policies. worldbank.org/sites/ppf3/PPFDocuments/Forms/DispPage.aspx?docid=3872 (дата обращения: 10.04.2020). Policy: WBG Policy: Sanctions for Fraud and Corruption, 2016. URL: https://policies.worldbank.org/sites/ppf3/ PPFDocuments/Forms/DispPage.aspx?docid=3868 (дата обращения: 10.04.2020). 
5. Рекомендации Всемирного банка по предупреждению и борьбе с мошенничеством и коррупцией в проектах, финансируемых за счет займов МБРР и кредитов и грантов MAP. - World Bank Guidelines on Preventing and Combating Fraud and Corruption in Projects Financed by the IBRD Loans and IDA Credits and Grants (dated October 15, 2006 and revised in January 2011). URL: https://documents.worldbank.org/en/publication/documentsreports/documentdetail/551241468161367060/guidelines-on-preventing-and-combating-fraud-and-corruptionin-projects-financed-by-ibrd-loans-and-ida-credits-and-grants (дата обращения: 10.07.2020).

6. Procurement In Investment Project Financing. Goods, Works, Non-Consulting and Consulting Services. Procurement Regulation for Investment Project Financing (IPF) Borrowers. Rev.2018. URL: http://pubdocs. worldbank.org/en/178331533065871195/Procurement-Regulations.pdf (дата обращения: 10.04.2020).

7. Directive: Bank Directive: Sanctions for Fraud and Corruption in Bank Financed Projects. 2016. URL: https://policies. worldbank.org/sites/ppf3/PPFDocuments/Forms/DispPage.aspx?docid=3871 (дата обращения: 10.04.2020).

8. The World Bank Group Sanctions System. URL: http://siteresources.worldbank.org/EXTOFFEVASUS/Resources/ Two-Tier-Sanctions-brochure-Final.pdf (дата обращения: 14.04.2020).

9. Definitions and Interpretive Guidelines. URL: https://www.ifc.org/wps/wcm/connect/a9e5a10049fe898dafa2bf02f 96b8a3d/Definitions_Interpretive_Guidelines.pdf? MOD=AJPERES (дата обращения: 05.11.2018).

10. Definitions and Interpretive Guidelines. URL: https:/www.ifc.org/wps/wcm/connect/a9e5a10049fe898dafa2bf02f 96b8a3d/Definitions_Interpretive_Guidelines.pdf? MOD=AJPERES (дата обращения: 05.11.2018).

11. IFC Sanctionable Practices. 2012. URL: https://www.ifc.org/wps/wcm/connect/topics_ext_content/ifc_external_ corporate_site/ac_home/sanctionable_practices (дата обращения: 12.10.2018).

12. IBRD/IFC/IDA/MIGA Policy. WBG Policy: Statute of the Sanctions Board. 2016. URL: https://policies.worldbank. org/sites/ppf3/PPFDocuments/Forms/DispPage.aspx?docid=3870 (дата обращения: 10.04.2020).

13. IFC Sanctions Procedures as adopted by IFC as of November 1, 2012. URL: https:/www.ifc.org/wps/wcm/connect/ d1c70b8049fe8971aed5be02f96b8a3d/Sanctions_Procedures+IFC.pdf? MOD=AJPERES (дата обращения: 10.07.2020).

14. Ibid.

15. Agreement for Mutual Enforcement of Debarment Decisions, 2010. URL: http://nadbg4.adb.org/oai001p.nsf/0/F7 7A326B818A19C548257853000C2B10/\$FILE/cross-debarment-agreement.pdf (дата обращения: 04.10.2020).

16. Cross debarment. URL: http://nadbg4.adb.org/oai001p.nsf/Home.xsp (дата обращения: 04.10.2020).

17. Agreement for Mutual Enforcement of Debarment Decisions, 2010. URL: http://nadbg4.adb.org/oai001p.nsf/0/F7 7A326B818A19C548257853000C2B10/\$FILE/cross-debarment-agreement.pdf (дата обращения: 04.10.2020). 